\title{
A study of validation of cultural value dimensions and plausible future authority style in the Indian context
}

\author{
Komal Sharma $^{1}$, Ranu Kumari ${ }^{2}$, Jaya Chitranshi ${ }^{3}$ \\ $\left\{\right.$ komals601@gmail.com ${ }^{1}$, ranu.kumari2019@sims.edu ${ }^{2}$, \\ jaya.chitranshi@sims.edu ${ }^{3}$ \} \\ Symbiosis International (Deemed University) ${ }^{1,2,3}$
}

\begin{abstract}
Cultural dimension model is an ongoing research by Global Leadership \& Organisational Behaviour Effectiveness (GLOBE) published in the late 1970s by Dr. Geert Hofstede. Till date, the research on the model gave rise to six dimensions regarding their impact on change: power distance, individualism, uncertainty avoidance, masculinity, long-term orientation, and indulgence. The present study is an attempt to validate the cultural value dimensions in the Indian context. Rokeach value survey result was analyzed by collecting the data from 90 students across India and analysis was done between the six Indian dimension scores of Hofstede and the ranking that came out of the value survey. Thus, the researchers tried to look for relationships existing between Indian Values and Hofstede's cultural value dimensions in today's Indian context.
\end{abstract}

Keywords: Hofstede's value dimensions, cultural survey, cultural dimensions, value survey, work culture, work value

\section{Introduction}

Studies utilizing an assortment of frameworks have demonstrated that national cultural values are identified in work environment practices, states of mind, and other organizational results, [21] [44] [29] [81] [70] [71].

Maybe the cultural classification by Geert Hofstede happens to be really compelling. It's been more than three decades since conveyance of Culture's Consequences took place: International contrasts in Work-Related Values [29], arousing a considerable number of empirical studies, but approval of Hofstede's culture value dimension framework in the Indian setting is as yet deficient. Our research intrigue resembles GLOBE project's primary objective of their research with an essential distinction. To be specific, the focus is not on the current workforce but future workforce, i.e. today's students. Our exploration addresses in this way center around what could be predicted: How do our upcoming administrators identify today's cultural values? What will their authority flair conceivably look like in future and by what means will it advance?

In the direction to fill this gap, we led a Rokeach value survey across India and connection examination was done between the six Indian dimension scores of Hofstede and the ranking that came out of the value survey. The point is to validate the relationship existing between the Indian values and Hofstede's cultural value dimensions. 
Along these lines, our decisions and suggestions should include past incentive audits, as our motivation was to validate cultural value framework in the Indian setting. As we will appear, without such a comprehensive validation, a significant part of the Hofstede-roused inquire about has stayed fragmented and, at times, redundant, and specialists can't benefit by the total information collected from an incorporated frame of quality study.

To start with, a concise review of Hofstede's cultural value dimensions is being given along with information on and how was it derived, and after that, we laid emphasis on the technique. Next, we survey discoveries, examine achievements and difficulties. At last, we give guidance for future Hofstede-motivated research.

\section{Objectives}

The present study has the following objectives:

a) To validate Hofstede's cultural value dimensions in the Indian context

b) To study what the future authority style conceivably will be

\section{Methodology}

Sample Technique- The sampling technique we used is a random sampling. It's a technique where each sample has an equal probability of being selected.

Sample size and sample characteristics- 90 students from various management institutes across India. Concentrating on this specific subset of students appears to be legitimized by the perception that the essential instructive foundation of the present managers is precisely in this field. After studying the data 15 outliers were found.

Sampling tool- A 15-minute questionnaire was created to measure the work values. Rokeach Value Survey (RVS) which is a standard survey created by social psychologist Milton Rokeach was used for the same. The survey measures two values, i.e. Terminal values and Instrumental values. Terminal values are the resultant values you want to get out of life. Instrumental values, on the other hand, are methods with which you seek to achieve the terminal values. The projected use of the instrument is to rank-order the 36 values further divided into 18 terminal and 18 instrumental values. The members in the study are expected to rank the 18 terminal qualities, trailed by the 18 instrumental values, in an order of significance of the value to them. Rank 1 means the most domineering value and rank 18 means the least significant value.

The 18 values that fall under the terminal values are comfortable life (relaxed or life 'at ease'), social recognition ( respect, acknowledgement and admiration), equality (equivalence or equal opportunity for all), true friendship (close alliance or companionship), exciting life (thrilling or stimulating and lively or full of life), wisdom (mature understanding or insight into life), family security (taking care or safekeeping of loved ones), world at peace (world without conflicts), freedom (independence or liberty and free choice), world of beauty (beauty of nature and exquisiteness), health (physical, mental and emotional well-being), pleasure (an amusing and restful life), inner harmony (freedom from internal conflict), salvation (redemption, eternal life), mature love (sexual and spiritual intimacy), self-respect (self-regard), national security 
(protection of nation from outbreak and violence), a sense of accomplishment ( a long-lasting contribution).

The 18 values that fall under the instrumental values are ambitious (hardworking and determined), independent (self-dependent, self-adequate), broad-minded (open-minded), intellectual (knowledgeable and rational), capable (proficient, adept and effective), logical (rational), clean (unsoiled), loving (affectionate and devoted), courageous (brave and bold towards one's own beliefs), loyal (faithful and trustworthy), forgiving (pardoning, forbearing), obedient (dutiful and compliant), helpful (supportive and caring), polite (courteous and well mannered), honest (authentic and truthful), responsible (in-authority and reliable), imaginative (inventive and creative), self-controlled (well-ordered and self-disciplined).

Proposed analysis- The collected ranking of the values is manually studied, and analysis is done of the ranking from the survey with that of Hofstede's culture dimensions.

\section{Literature review}

[29] defined culture as the amalgamated programming of the mind that differentiates the affiliates of one cluster from those of another. Culture entails the trend of thought process that passes from generation to generation, that parents transfer to their offspring's, leaders to their followers, educators to their students, friends to their friends, and vice versa. It's the meaning that we take out from various aspects of life; the way we look at the realm and our part in it; in our beliefs, that is, whatever we consider as "good" and "evil"; in our collective views, what we consider as "true" and what we consider as "false"; in our arty expressions, what we deliberate as "beautiful" and as "ugly". Culture, even though fundamentally dwells in individuals' brains, winds up in the establishments and unmistakable results of the common public, which strengthen the psychological schemes in their turn. Supervision inside the common public is compelled by its social setting as it becomes difficult to position the doings of individuals without a thoughtful understanding of their qualities, convictions, and articulations.

The distinction between values as desired and desirable is recognized by [31], [33]. He proposes that values as desired are more firmly identified with behavior than values as desirable and are more grounded indicators of behavior. Such a distinction was advocated by the following researchers: [31], [50].

[72] characterizes values as alluring states, items, objectives, or practices rising above particular circumstances and connected as regularising principles to judge and pick among elective methods of conduct. [77] exemplifies work values as the end esteems, for example, fulfilment, excellence or reward, that people look for from their work. Decisions, objectives and mentalities are influenced by work values [10] [68] and are firmly associated with inspiration [28] [58]. Work values happen to be vital thought in the work environment since these anticipate activities and decisions [69], coordinate conduct [28], and influence various organization results, for example, judgment and basic leadership, work gratification, commitment, and execution [16] [10] [57] [73] [41]. Hofstede's work is groundbreaking however questionable [78]. The main issue against the investigation is the problem of diminishing culture to excessively shortsighted dimensions; test containing just one company; overlooking culture changes; and neglecting to consider cultures heterogeneity [43]. The GLOBE study came after the Hofstede model and was 
structured to recreate and develop the Hofstede model [84]. The examination is enormously impacted by Hofstede model in the selection of factors and the nine societal scales in the study share labels with the Hofstede measurements [74]. In spite of the fact that the investigation is viewed as a standout amongst the latest investigations [9], it is likewise scrutinized for being US-driven; it neglects to catch what is proposed through the survey; the various cultural dimensions lack parsimony [33]. Furthermore, the investigation still faces a few constraints that Hofstede model has, for example, the generalizability, the questionnaire, the total of individual data to national data. Regardless of the criticism, various literature has been published on Hofstede's cultural dimension on both hierarchical and national dimensions is proof of the wide acknowledgment of his structure. This framework not just has a more prominent effect than other cultural frameworks but is recognized in culturally diverse research in light of its clearness and parsimony [78]. Despite the fact that [15] revealed irregularities in Hofstede's result in their investigations, their worries depended on research results that were duplicated on a little scale, and no generally acknowledged substitute models have been proposed to date.

\subsection{Cultural dimensions by Hofstede}

In a study conducted on employee attitudes in the overall subsidiaries of IBM Corporation, Hofstede recognized four differentiating sets of cultural dimensions that can be utilized to show general uniformities and differences in many various societies across the globe. These are:

\subsubsection{Large versus small power distance}

It depicts the degree to which the individuals from a general society recognize that the power in foundations and associations is circulated unequally. High Power Distance social orders recognize that there are various segregations in which every person has a place and this reality is accepted by all. Small Power Distance societies work towards power parity and request legitimization for power imbalances. The emphasis is on knowing how individuals handle power distance when they are at the receiving end. The idea of social axioms comes from the understanding of what the society believes to be a general truth i.e. the general behavior in a society. Like the notion that the ones with power tend to exploit others and how various social institutions are biased toward the rich [49].

\subsubsection{Strong versus weak uncertainty avoidance}

This measurement tells us how much people feel weakened by the unknown i.e. uncertainty. Strong Uncertainty Avoidance societies tend to go by the books. They do not believe in bending the rules and are narrow minded when it comes to something unconventional. On the other hand, societies displaying Weak Uncertainty Avoidance practice a more casual state of mind. The central focus of this measurement is to check how the general public responds to the uncertainty. [36] conclude that individual characteristics, for example, neuroticism and pleasing-ness have factually huge connections with vulnerability shirking and masculinity

\subsubsection{Individualism versus collectivism}

The fundamental preface is the connection among people and their fellow people [30]. This esteem measurement identifies with an inclination for a freely sew social structure in which people rely on themselves and their close families [31]. Individualism is all about having an inclination wherein people deal with themselves i.e. work for themselves. Concerning its inverse - Collectivism, it remains for close nit society in which people can expect their relatives or 
individuals from a community to take care of them in return for the loyalty and dedication. This is a measurement of 'I' or 'we'.

\subsubsection{Masculinity versus femininity}

The essential idea of this measurement is the division of responsibility between the genders in the society [30]. In a masculine society, where a boosted social sex role exists, men, for the most part, play a progressively self-assured position and ladies a more administration arranged and soft role. The masculine cultural value dimension identifies with courage and material achievement [31]. Masculine society stresses mainly on estimations of accomplishment, chivalry, self-assuredness, and material achievement while Femininity is associated with societies which are inclination towards teamwork, humbleness, and the drive to find meaning in life and work. The vital issue of this measurement is the manner in which social orders dispense social roles to the genders.

\subsubsection{Long versus short-term orientation}

This measurement remains for the manner in which individuals support even minded, futuresituated temperance's. Societies with a short-term orientation, by and large, have very little inclination to save for the future, and show an emphasis on accomplishing instant gratification. In societies with a long-term orientation, individuals trust that one's reality depends to a certain extent on surroundings, situation and time. They demonstrate a flexibility to adjust to changing situations, exercise solid tolerance and contribute tirelessly in accomplishing results. As far as the decision of Confucian thoughts, this measurement catches the degree to which individuals have a future-oriented attitude as opposed to concentrating on the present. Along these lines, on one end it mirrors a dynamic, future-oriented viewpoint, whereas on the other end it mirrors a progressively static, tradition-oriented point of view [35]. In social orders with long-term inclination, individuals know numerous certainties, furthermore, are thought to have progressively adaptable reasoning and broad mind. Consequently, they are seen to be thrifty with cash venture. Connections are to a great extent sorted based on status. On the other hand, societies with short-term orientation believe that there is just a single supreme truth and anticipate fast outcomes, which speaks to an increasingly static frame of mind [4]. Also, regardless of that the GLOBE tried to extend Hofstede model, a portion of the worries in regards to constraints of this investigation have remained, counting the absence of information generalizability crosswise over populace and time as well as the capacity to coordinate the culture measure with information coming from later timespans [79].

\subsubsection{Indulgence versus restraint}

Indulgence societies are those, that to a certain extend practice open fulfilment of essential human motivators acknowledged with taking charge of life head on and having a gala time while at it. Restraint societies suppress gratification of desires and controls it by practicing strict social standards.

Using measures of every one of the social qualities for a gathering of nations incorporated into the examination, Hofstede groups societies into diverse cultural clusters. 


\subsection{History of Dimensions}

Uncertainty Avoidance and Power Distance had been mentioned on the hierarchical level of social examination by [11] and [59], before Hofstede.

Collectivism was, alongside its antonym Individualism, effectively related to the mental, sociological and anthropological writing, before [29] characterized it as a cultural dimension. [61], for instance, mentioned this dimension as Collectivity versus Self-accentuation. [44] discussed Collaterality versus Individualism, and [3] used the terms Community versus Agency. [80], work on Multidimensionality of Individualism versus Collectivism gave way to GLOBE's In-bunch Collectivism. Whereas GLOBE's analysts [38] later coined the term Institutional Collectivism.

Gender Egalitarianism and Assertiveness, as a cultural dimension expand on [29] Masculinity/Femininity measurement yet handled independently because of the overwhelming feedback of Hofstede's unique measurement [37] [38] [58].

The dimension Future Orientation is introduced in [44] Past, Present and Future Orientation, centers around the worldly introduction prevailing in general public. Even though [31] likewise discussed Long-term introduction, [38] contends that GLOBE's Future Orientation is just possibly identified with Hofstede's build.

Performance Orientation and Humane Orientation, are the two measurements in the GLOBE inquire that Hofstede did not quantify. Expanding on [52] [53] discoveries, Hofstede said individuals have different requirements for accomplishment or for continuous improvement, while the measurement Humane Orientation was coined by [44] meaning "human instinct as good versus bad". The underlying productions coming from the GLOBE venture have just set off a distinctive discussion in the writing with regards to the number and substance of the measurements and their oddity or potentially cover with Hofstede's work [33] [40] [75] [84] [5]. GLOBE discoveries, prior conceptualizations of culture have been rethought concerning the effect of culture on administration [13].

\section{Results}

Hofstede cultural dimensions for India

\subsection{Power distance}

Degree to which the low power members of society within a country agree to and expect that power are unequally distributed.

India has a high score on this dimension, 77, which indicates that there is an appreciation for hierarchy.

For comparison with power distance, we have taken the following values in consideration from the survey because these values best represent power distance. Equality stands for a sense of association and equal chances for all. World at peace means a world which is conflicts free. National Security means protection of the nation from attacks such as terrorism, war and espionage. Obedient means compliance with the orders, submission to authority. 
Table 1. RSV Rankings for Power distance

\begin{tabular}{lll}
\hline Values [Terminal (T), Instrumental (I)] & Rank & Percentage of people \\
\hline Equality (T) & 1 & $12.2 \%$ \\
World at peace (T) & 1 & $10 \%$ \\
National security (T) & 18 & $11.1 \%$ \\
Obedient (I) & 1 & $2.2 \%$ \\
\hline
\end{tabular}

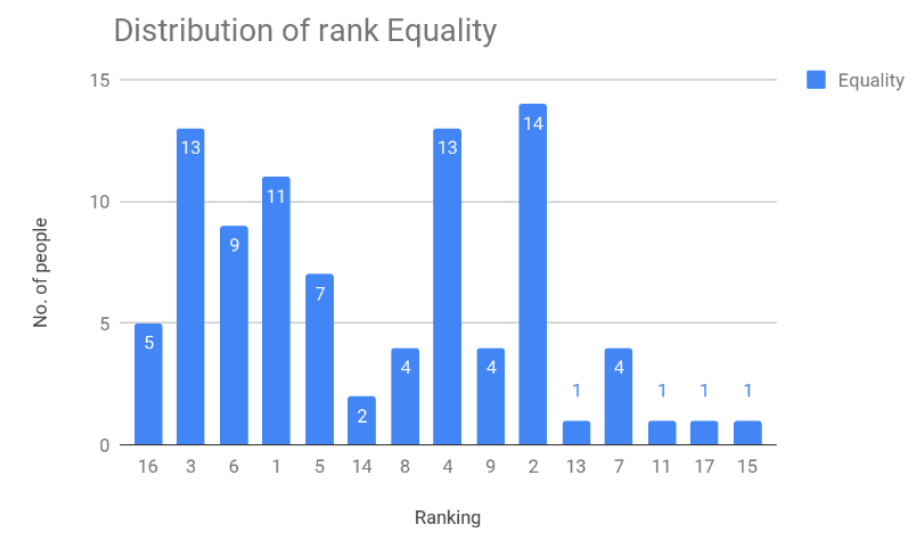

Fig. 1. Distribution of rank Equality (Source: Authors creation)

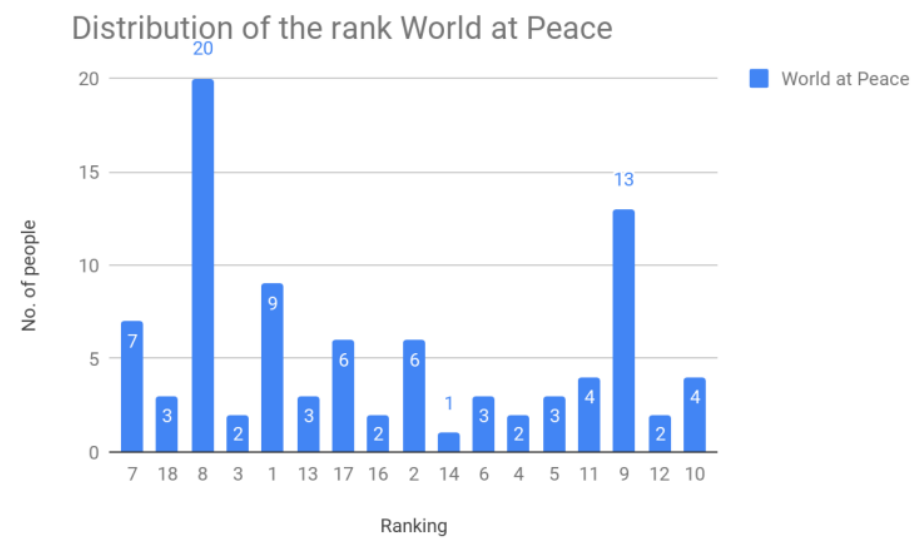

Fig. 2. Distribution of rank World at Peace (Source: Authors creation) 


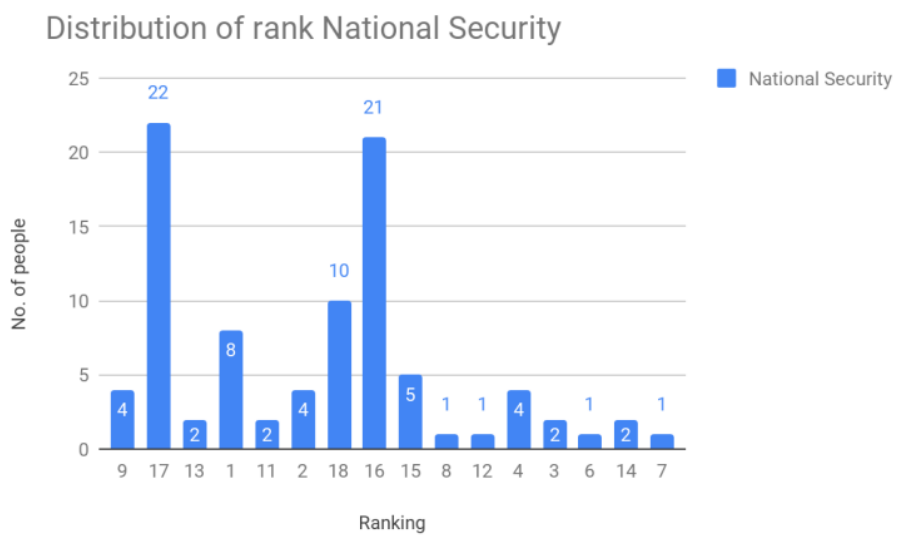

Fig. 3. Distribution of rank National Security (Source: Authors creation)

\section{Distribution of rank Obedient}

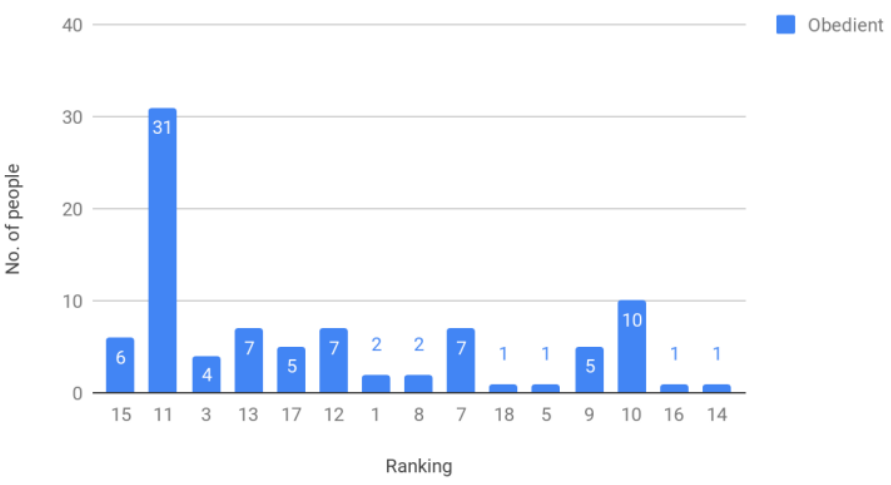

Fig. 4. Distribution of rank Obedient (Source: Authors creation)

\subsection{Individualism}

The concept of individualism is about being self-reliant, it is the degree of interdependence among the members of society. India happens to have traits of both collectivistic and individualistic society with a somewhat intermediate score of 48 .

For comparison with individualism, we take into consideration the following values from the survey. Inner harmony means freedom from internal conflict, peace of mind with selfacceptance. Sense of accomplishment is a feeling that you have achieved something great and made a lasting contribution. Ambition means having a strong desire to achieve something for you. Independence means, being self-reliant and self-sufficient.

For comparison with collectivism, Social recognition means the respect and admiration that comes from one's work. True friendship means close companionship that one looks for. Family 
security means having loved ones who you can count on. Loyalty means being faithful to friends or a group of people. Helpful means are working for the welfare of others.

Table 2. RSV Rankings for Individualism

\begin{tabular}{lll}
\hline Values [Terminal (T), Instrumental (I)] & Rank & Percentage of people \\
\hline Social recognition (T) & 1 & $7.7 \%$ \\
& 18 & $13.3 \%$ \\
True friendship (T) & 1 & $12.2 \%$ \\
Family security (T) & 1 & $8.8 \%$ \\
Inner harmony (T) & 1 & $11.1 \%$ \\
Sense of accomplishment (T) & 1 & $5.5 \%$ \\
Ambition (I) & 1 & $26.6 \%$ \\
Independence (I) & 1 & $25.5 \%$ \\
Loyalty (I) & 1 & $7.7 \%$ \\
Helpful (I) & 1 & $6.6 \%$ \\
\hline
\end{tabular}

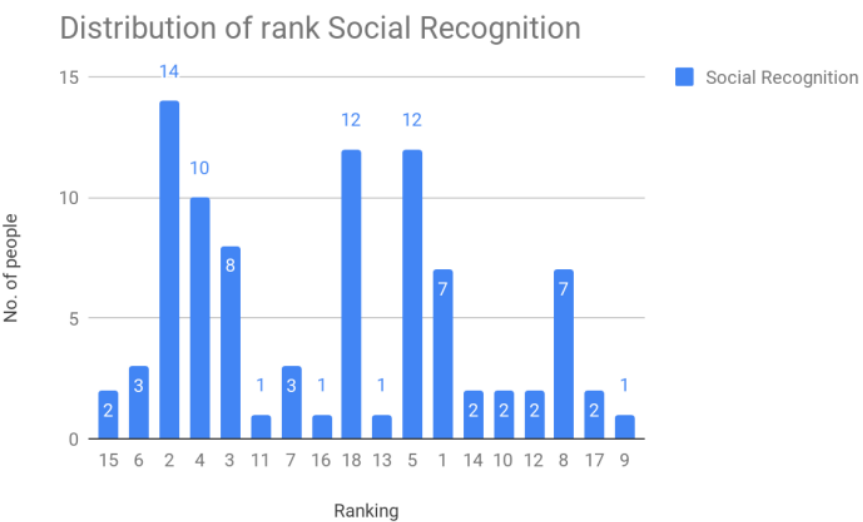

Fig. 5. Distribution of rank Social Recognition (Source: Authors creation 


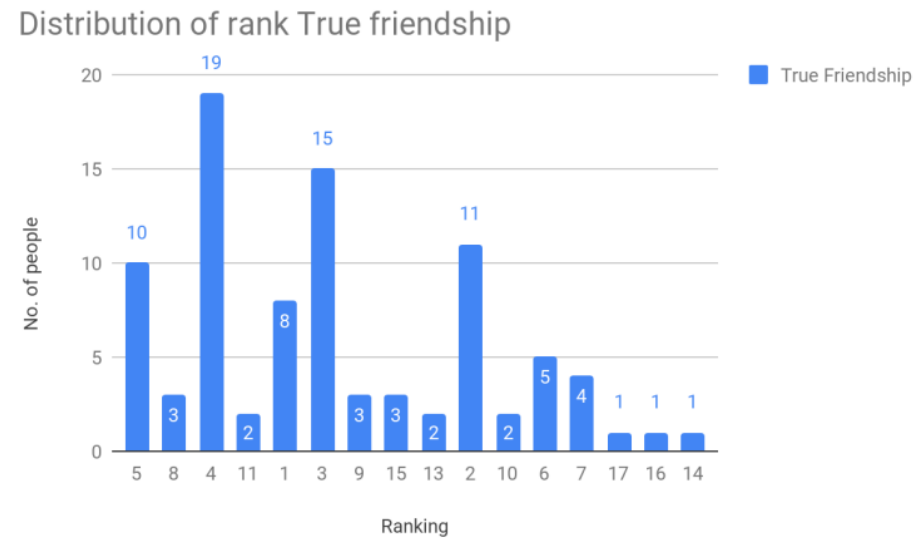

Fig. 6. Distribution of rank True Friendship (Source: Authors creation

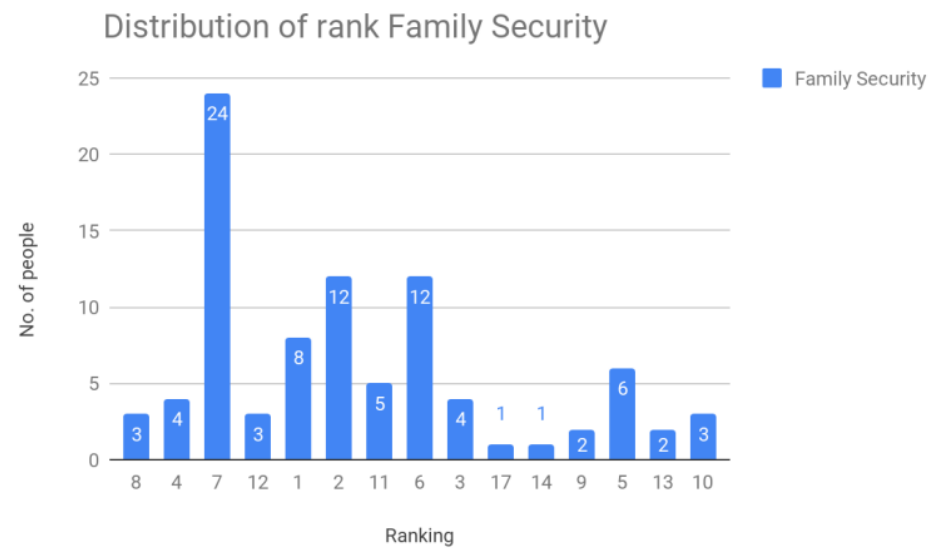

Fig. 7. Distribution of rank Family Security (Source: Authors creation)

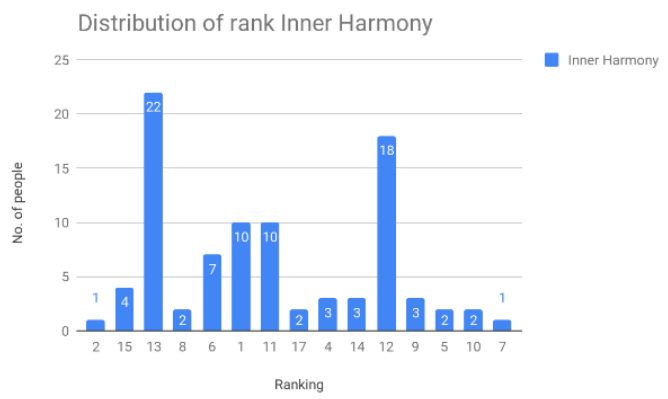

Fig. 8. Distribution of rank Ambitious (Source: Authors creation) 


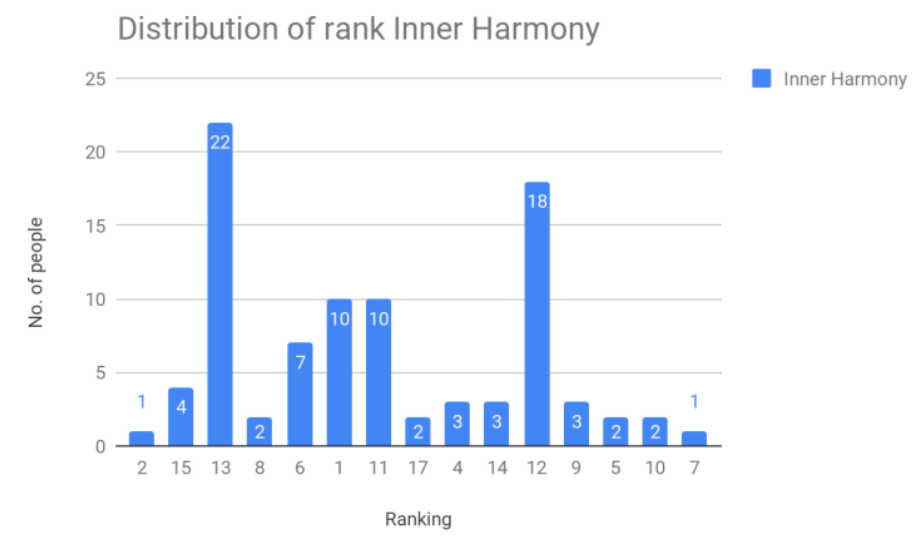

Fig. 9. Distribution of rank Inner Harmony (Source: Authors creation)

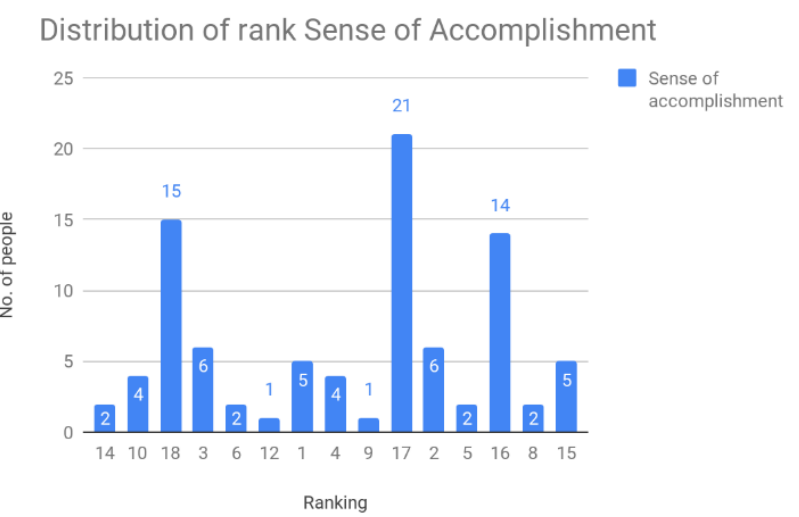

Fig. 10. Distribution of rank Sense of Accomplishment (Source: Authors creation)

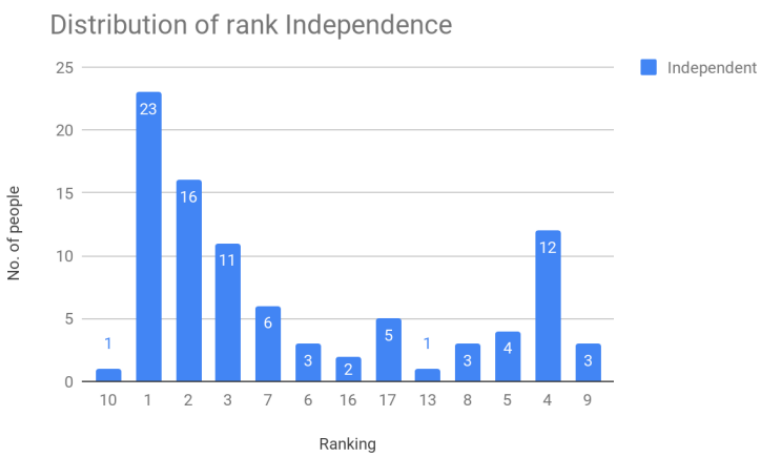

Fig. 11. Distribution of rank Independence (Source: Authors creation) 


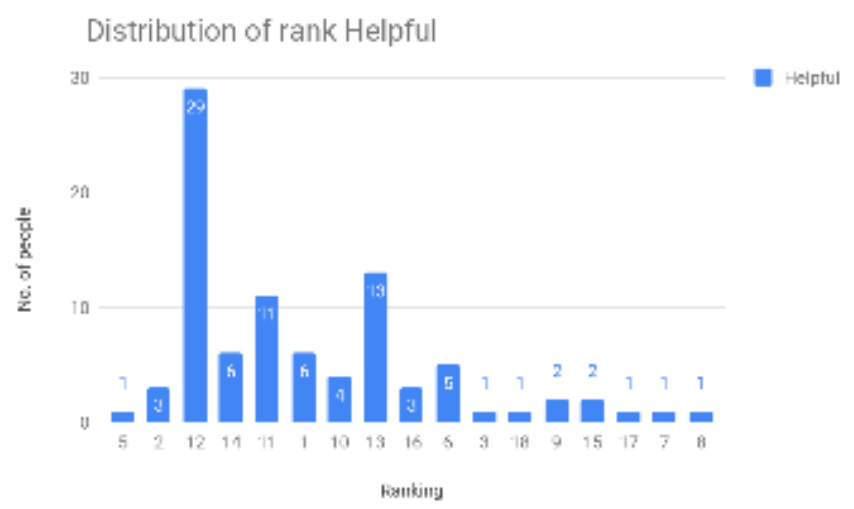

Fig. 12. Distribution of rank Helpful (Source: Authors creation)

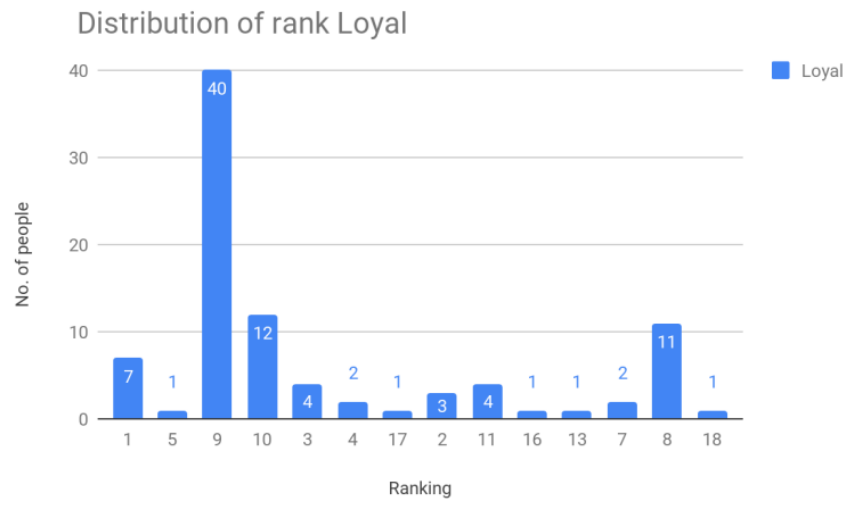

Fig. 13. Distribution of rank Loyal (Source: Authors creation)

\subsection{Masculinity}

India is considered a Masculine society as it scores 56 on this dimension. The fundamental issue comes out to be the motivational factors: Having the aim to come on top and be the best (Masculine) or fondness of what you do (Feminine).

For comparison with Masculinity, we take into consideration the following values from the survey. Social recognition means the respect and admiration that comes from one's work. Selfrespect means knowing your self-worth. Sense of accomplishment is a feeling that you have achieved something great and made a lasting contribution. Ambition means having a strong desire to achieve something for yourself.

For comparison with Feminine, the following value is considered. Inner harmony means freedom from internal conflict, peace of mind with self-acceptance. 
Table 3. RSV Rankings for Masculinity

\begin{tabular}{lll}
\hline Values [Terminal (T), Instrumental (I)] & Rank & Percentage of people \\
\hline Social recognition (T) & 1 & $7.7 \%$ \\
Self-respect (T) & 1 & $7.7 \%$ \\
Sense of accomplishment (T) & 1 & $5.5 \%$ \\
& 18 & $16.6 \%$ \\
Inner harmony (T) & 1 & $11.1 \%$ \\
Ambition (I) & 1 & $26.6 \%$ \\
\hline
\end{tabular}

Fig. 14. Distribution of rank Self respect (Source: Authors creation)

\subsection{Uncertainty avoidance}

The extent to which the societies associate fear with the unknown situations and uncertainty and have set systems and beliefs in order to avoid these unknown situations is shown in the score of Uncertainty Avoidance. India scores 40 on this dimension which means India has a mediumlow preference for avoiding uncertainty.

For uncertainty avoidance, the values we investigate are as following. Comfortable life means a prosperous life filled with relaxation. Forgiving here implies tolerance to other mistakes and willing to pardon others. Exciting life means a life filled with challenges that are stimulating.

Table 4. RSV Rankings for Uncertainty avoidance

\begin{tabular}{lll}
\hline Values [Terminal (T), Instrumental (I)] & Rank & Percentage of people \\
\hline Comfortable life (T) & 1 & $27.7 \%$ \\
Exciting life (T) & 1 & $5.5 \%$ \\
Forgiving (I) & 1 & $3.3 \%$ \\
\hline
\end{tabular}




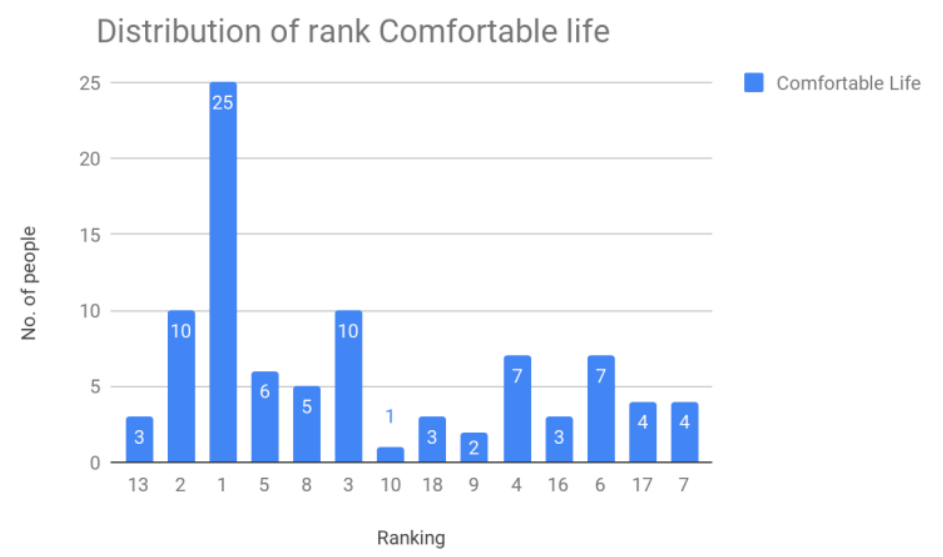

Fig. 15. Distribution of rank Comfortable life (Source: Authors creation)

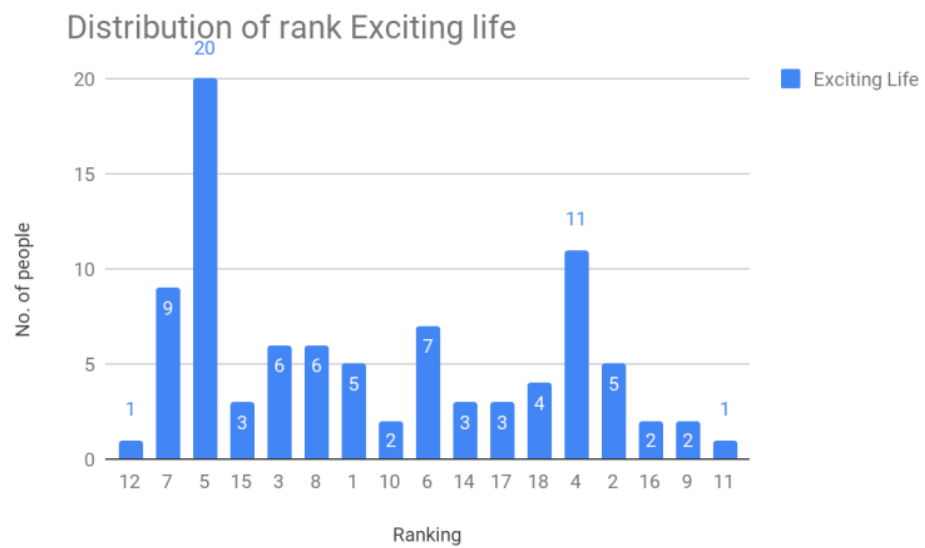

Fig. 16. Distribution of rank Exciting life (Source: Authors creation) 


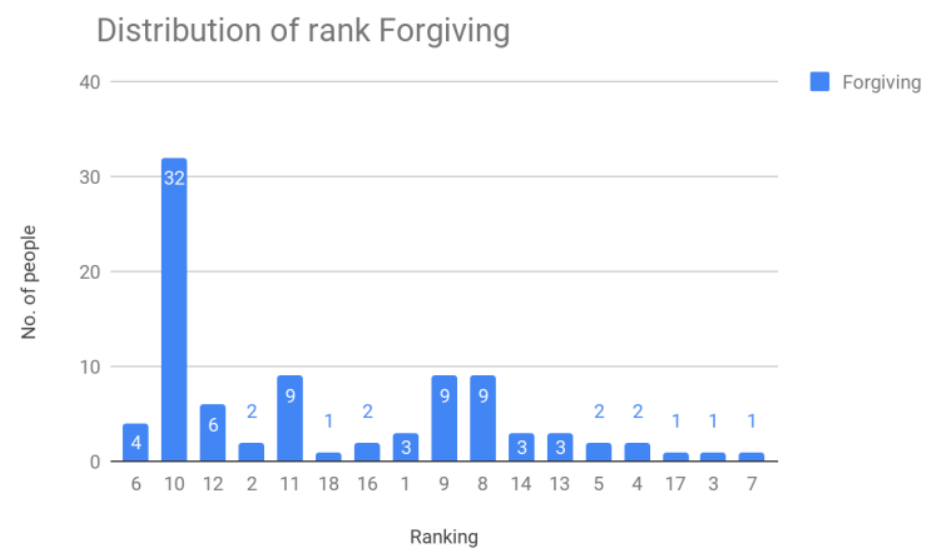

Fig. 17. Distribution of rank Forgiving (Source: Author creation)

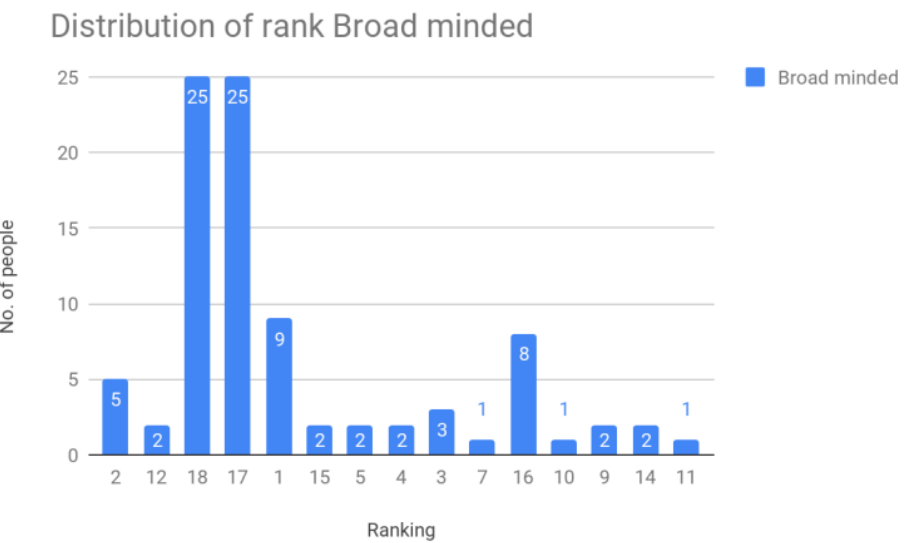

Fig. 18. Distribution of rank Broad minded (Source: Author creation)

\subsection{Long term orientation}

It is about how much a society preserves with its past while dealing with the challenges of the present and the future. India scores an intermediate 51 in this dimension, which says that the Indian culture does not have a dominant preference.

For long-term and short-term orientation values that are studied are as follows. Forgiving here means tolerance to other mistakes and willing to pardon others. Wisdom means a mature understanding of life that comes from having rich experiences, knowledge and good judgment. Broad-minded means being open-minded and liberal with different views and reactions and not being easily offended. 
Table 5. RSV Rankings for Long term orientation

\begin{tabular}{lll}
\hline Values [Terminal (T), Instrumental (I)] & Rank & Percentage of people \\
\hline Wisdom (T) & 1 & $16.6 \%$ \\
Forgiving (I) & 1 & $3.3 \%$ \\
Broad minded & 1 & $27.7 \%$ \\
\hline
\end{tabular}

Ditribution of rank Wisdom

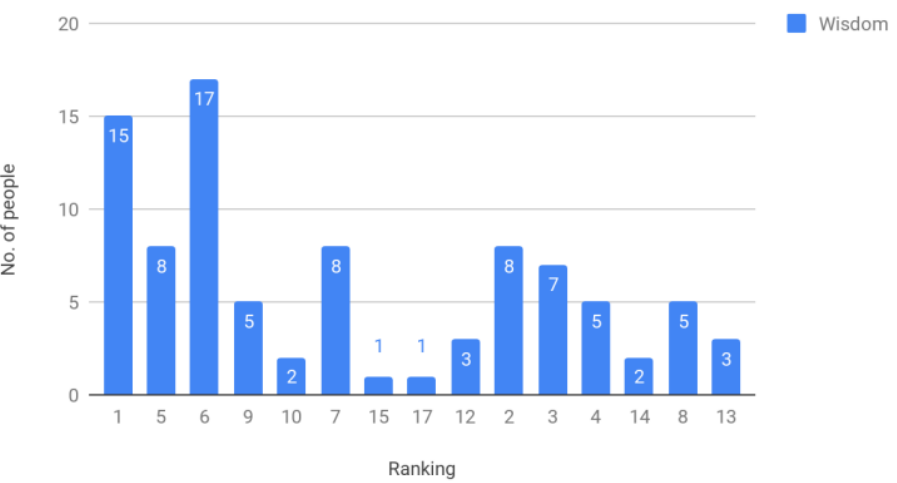

Fig. 19. Distribution of rank Wisdom (Source: Author creation)

\subsection{Indulgence}

The degree to which society is okay with getting indulged in urges and impulses is Indulgence. India scores low in this dimension i.e. 26, which indicates a culture of Prudence or Restraint.

To validate restraint, the following values were considered. Exciting life means a life filled with challenges that are stimulating. Social recognition means the respect and admiration that comes from one's work. Pleasure here means having an enjoyable leisurely life. Self-control means restraining oneself and practicing self-discipline. Salvation implies conservation from harm and aiming for eternal life. 
Table 6. RSV Rankings for Indulgence

\begin{tabular}{lll}
\hline Values [Terminal (T), Instrumental (I)] & Rank & Percentage of people \\
\hline Pleasure (T) & 1 & $2.2 \%$ \\
Social recognition (T) & 1 & $7.7 \%$ \\
Exciting life (T) & 1 & $5.5 \%$ \\
Self-control (I) & 1 & $13.3 \%$ \\
Salvation (T) & 18 & $30 \%$ \\
\hline
\end{tabular}

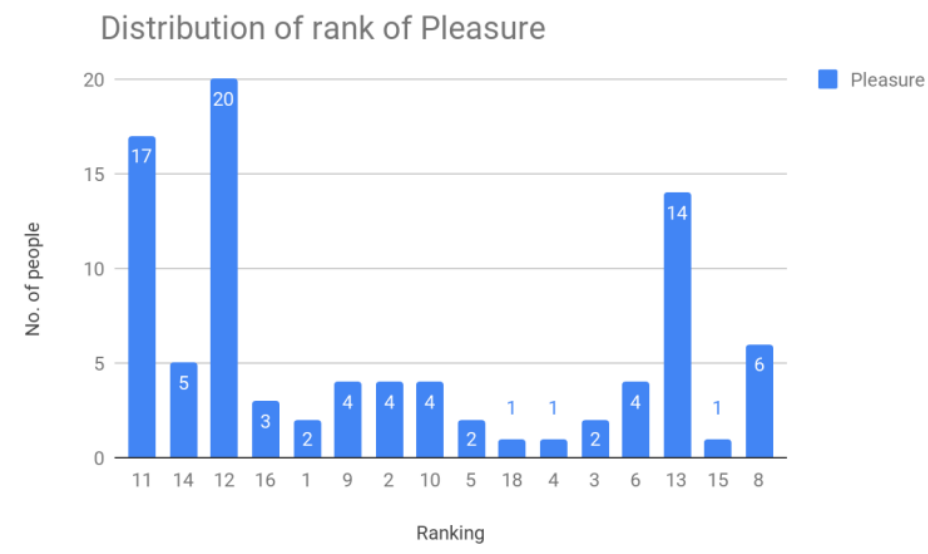

Fig. 20. Distribution of rank Pleasure (Source: Author creation)

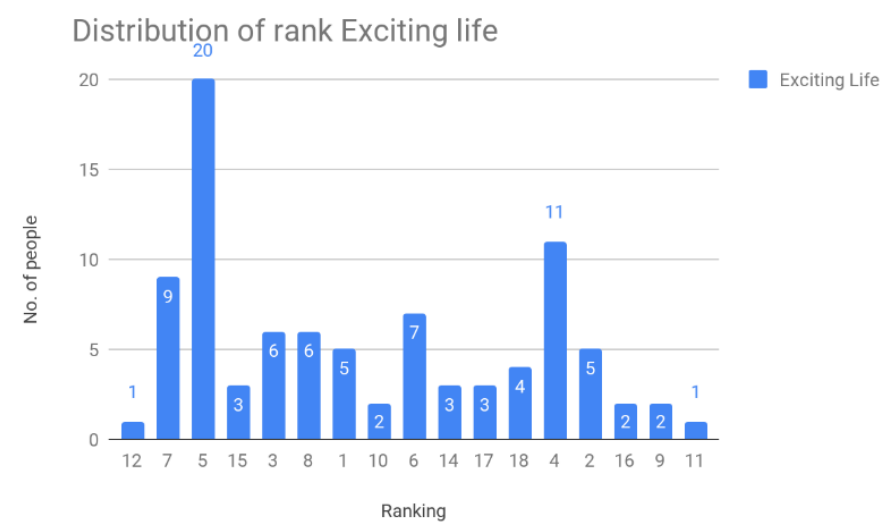

Fig. 21. Distribution of rank Exciting life (Source: Author creation) 


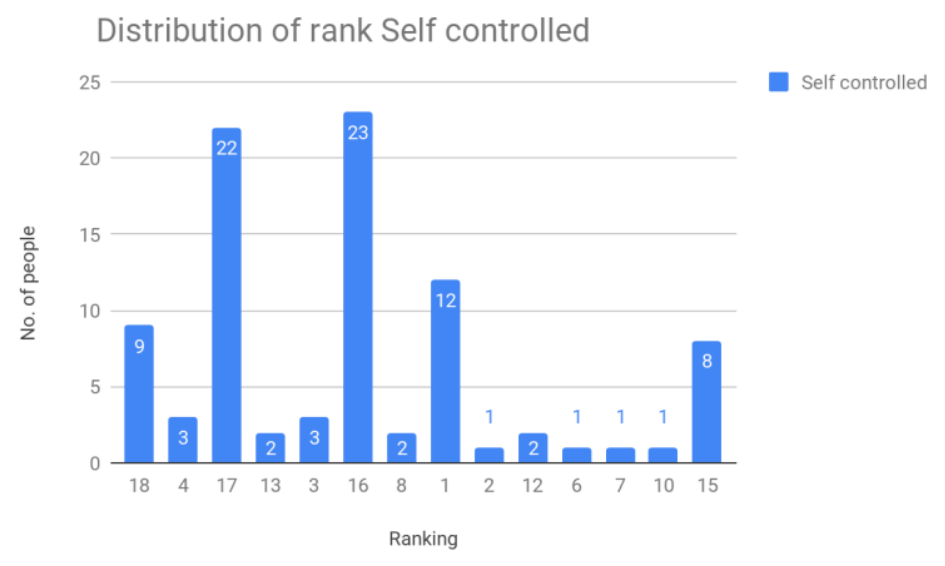

Fig. 22. Distribution of rank Self controlled (Source: Author creation)

Distribution of rank Salvation

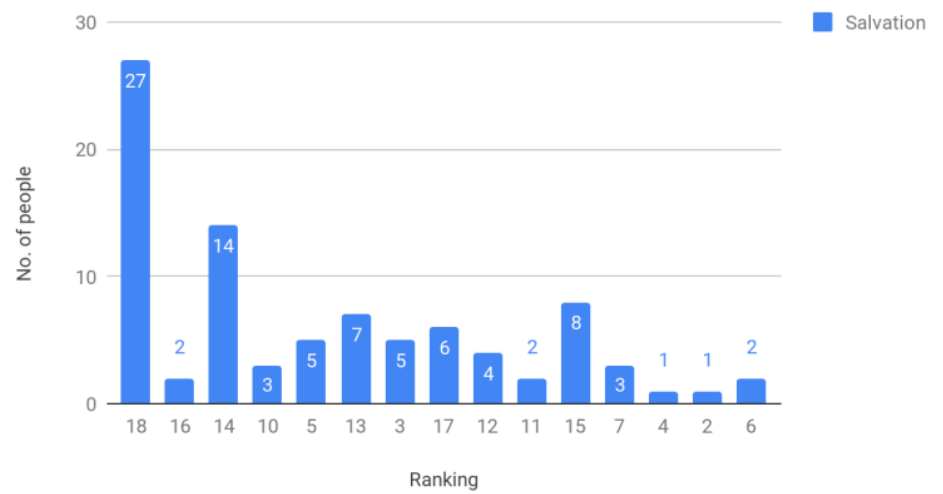

Fig. 23. Distribution of rank Salvation (Source: Author creation)

\section{Discussion}

\subsection{Findings}

\subsubsection{Power distance}

The results of Hofstede's study show that a top-down structure in the Indian society and organizations is quite significant. The Indians attitude toward power distance can be described as that of dependent on the power holder for guidance, okay with disparity and acceptance of unequal rights distributed among the privileged, and the underprivileged. 
Whereas the results of the survey suggest that there is a change in the way people look at equality. Equality has been given top rank i.e. rank 1 to 5 by $64.4 \%$ which means that people seek equal opportunities at the workplace.

Results of the European Values Survey indicates that there is a relationship between the central values and age [42]. Therapists [57] [25] make us mindful that individuals' values go through a lot of change in their lifetime. Among the young time frame, self-indulgent values take preceding, while later on the power turn out to be more vital lastly, moral values and selfactualization take preceding. World at peace has been given middle rank i.e. rank 8 to 10 by $41.11 \%$ which suggests moderate importance is placed on the same. Obedience has been given rank 10 and 11 by $45.55 \%$ which suggests people generally practice obedience. National security has the lowest rank 16 and 17 by the majority, i.e. $47.77 \%$ which implies it is of least importance for people.

\subsubsection{Individualism}

The collectivism shows that people prefer associating to a group wherein individuals take decisions with what's good of one's defined group. This influences actions of the individuals in the group to a great extent, and the main influencers namely judgement of close ones like family, friends, neighbors and various other social groups. Groups play a critical role in shaping an individual's perspective and mindset even though the individual himself/herself is a smaller part of the group. This is why for a collectivist, rejection by peers and fall low on the priority of the peers leaves him with a sense of emptiness. The Individualist aspect of Indian society originates from its prevalent religion/philosophy - Hinduism. Hinduism believes in the cycle of life that entails in the belief of death and rebirth, with the belief that each rebirth is reliant upon the individual's previous life deeds. Hence, the belief originates that people should be responsible while they lead their lives as it will impact how life will come to them upon rebirth. The concept of "Karma" is indeed a very prevalent idea in Hinduism that focuses on the outcomes in the next life as based on how we fare today. The emphasis put upon how the individualism interacts with the collectivist inclinations of the Indian society which gives it an intermediate score on this dimension.

Social recognition received the top rank, i.e. rank 1 to 5 by $56.66 \%$. True friendship gained high rank from $70 \%$. Family security had a majority in moderate rank, i.e. rank 6 to 8 by $43.33 \%$. Loyalty was given rank 8 to 10 by $70 \%$ which makes it fall into the moderate category. The value Helpful also had the majority of its rank, i.e. 58.8\% in 11 to 13 . When we look at the individual values, inner harmony had a rank of 11 to 13 in 55.5\%. Ambition had the majority of its ranks from 1 to 5 , i.e. $55.55 \%$. Independence had a rank from 1 to 4 by $68.8 \%$. Sense of accomplishment had a majority in the low rank i.e. rank 16 to 18 at 55.55\%. Social work values incorporate essential associations with partners and work environment. Generations $\mathrm{X}$ and $\mathrm{Y}$ put great emphasis on social work values as compared to Baby Boomers do [1] [85] [47] [64] [60]. Baby Boomers are faithful, optimistic and require secure workplace [76]. Generation Xers are doubtful and disinterested with authority in comparison to Baby Boomers who look up to authority for direction [22]. Gen Y's work approach has been that of strong work-life balance [39], where individual objectives take preceding over the business objectives. Adding on to that, Gen Y tend to hop jobs [83]. 


\subsubsection{Masculinity}

When it comes to ostentation or say, showcasing the success and power, India is very Masculine. The flash of success and power, the label of a designer brand that goes with all the advertisement of how well one's off, is widely spread. At the same time, India is a country with the most extended surviving cultures that makes it a religious country where millions of deities practice religious philosophies laid by various Indian schools of Philosophy. Therefore, India is rich when it comes to lessons in the value of humility and abstinence or sobriety. This happens due to societies natural inclination to Masculine display. Masculine countries lay focus mainly on succeeding and achieving in whatever work they do which is mostly validated by material gains. Visibility of success is significant in the workplace.

Social recognition received the top rank, i.e. rank 1 to 5 by $56.66 \%$. Self-respect had a majority in the moderate rank of 14 to 16 by $53.33 \%$. Sense of accomplishment had a majority in the low rank i.e. rank 16 to 18 at $55.55 \%$. Inner harmony had a rank of 11 to 13 in $55.5 \%$. Ambition had the majority of its ranks from 1 to 5 , i.e. $55.55 \%$. Intrinsic values are related to discovering significance and enthusiasm for one's work. Different examinations have recorded noteworthy contrasts among the generations regarding inherent work values. Generation $\mathrm{X}$ and Generation $\mathrm{Y}$ has been seen placing emphasis on gaining skills and knowledge related to work, then Baby Boomers [76] [2] [64]. Instrumental work values help individuals in gaining material accomplishments from their occupations. In many studies on generation contrasts with respect to extrinsic work values, Generations $\mathrm{X}$ and $\mathrm{Y}$ rate extrinsic values, such as monetary returns, position, glory, achievement, higher than Baby Boomers do [7] [8] [85] [83] [60]. Gen Y has shown more drive for status in their occupations as often, they are eager and impatient in expecting quick rewards [20] [60].

\subsubsection{Uncertainty avoidance}

India is a country that takes patience quite literally as people comfortably settle-in for whatever comes their way, they are not driven to make initiatives to change what in general terms is not comfortable. India comes out to be a country with a high tolerance for the unexpected. Rules are often sidestepped as one relies on methods to find a way round to "bypass the system". The word "adjust" is often used widely meaning a range of thing, from not acknowledging the rules being disdained to finding innovative solutions to a seemingly strong problem. This becomes the source of pain as well as the most empowering aspect of the country. In India "nothing is impossible", so long as one knows how to "adjust".

Comfortable life had a rank of 1 to 3 for $50 \%$ of the sample. Exciting life had a majority in rank 4 to 7 by $52.22 \%$. Forgiving had the rank 8 to 11 by $65.55 \%$. Generation $\mathrm{Y}$ is from the time when nation turned out to be more prosperous through progression and change strategies. India grew tremendous in its IT capability, and in 2008, 34 Indian organizations were in Forbes Global 2000 positioning. The individuals from this age have huge monetary chances, are innovatively able what's more, have solid entrepreneurial aptitudes. They are appropriate for worldwide connection [14].

\subsubsection{Long-term orientation}

India shows open-mindedness for religions from all over the world. In India, Hinduism is regarded as a philosophy of life more than a religion to follow; it's a beautiful unification of different practices, views, opinions and obscure beliefs. India accepts many truths and these 
truths rest on the pursuer. These truths come from historical sagas of many warrior led happenings. Societies scoring high on this dimension have high tolerance to lack of punctuality, an alternative plan based on the current reality and is determined to discover destined route along the way rather than following an exact plan.

Wisdom has the rank of 1 to 3 for $33.33 \%$ of sample size. Broadminded has the rank of 16 to 18 for $64.4 \%$ of the sample.

\subsubsection{Indulgence}

Pessimistic and cynic societies tend to score low in this dimension. Also, restraint societies do not put much focus on leisure time, unlike the indulgent societies. The prudent society emphasizes on control on indulgence of wants. People in these societies have a belief that indulging themselves is wrong at the same time their decisions are influenced by the social norms.

However, Self-control was at the lower end. Rank 15 to 18 showed a majority of $68.88 \%$. Pleasure was given a moderate ranking by the majority of $56.66 \%$. Salvation was as well in the lower end with ranking 14 to 18 by $56.66 \%$. Exciting life had a majority in rank 4 to 7 by $52.22 \%$. Social recognition received top rank, i.e. rank 1 to 5 by $56.66 \%$. The Gen $Y$ have a sense of entitlement attached to the work they do irrespective of the level of execution by them. A few examinations bear witness to the expanded feeling of entitlement shown by Generation Y. Expanded narcissism is a noteworthy reason for this feeling of privilege among individuals from Generation Y [82]. Indeed, even the students of Generation Y show a feeling of entitlement when it comes to evaluation, inconsequential to their academic performance [19]. [60] also found that there is a disconnect between rewards and performance of Generation Y. Elevated levels of entitlement like this can be hazardous in the working environment, as it leads to struggle, injurious conduct, work dissatisfaction, and low employment fulfilment levels [23] [24].

\subsection{Implications}

a) Finding has shown that future managers are very sensitive to equality. Change in the attitude of today's generation regarding the power distribution is seen. The degree of acceptance to power inequality has reducing. There will no more be appreciation for hierarchy. Our future managers are becoming more aware on what is right and how equality plays a major role in their respective work environments. It becomes critical for bosses to give genuine feedback regularly especially with the younger employees [7] [17] [51] [67]. Therefore, a regular and informal feedback becomes more essential than a conventional yearly feedback meeting. Generation Y are characteristically drawn towards challenging jobs. A regular feedback keeps a check on the changes that has been taking place not just in the minds of the employees but also in the external world around them as that influences their mindset majorly. They demand for equality but they also prefer working hard on tasks that challenges them. As it shows that it is being believed by our future managers that basic rights should be given but not by keeping at stake the work challenges. Rather it should be well deserved by the employees. They search for occupations that give chances to utilize their capacities. It is in this manner prescribed that organizations hope to provide Generation $\mathrm{Y}$ with opportunities that are stimulating and include more prominent accountability [62]. 
b) Dealing with the elements of different generational working together is a challenge for managers today. Mostly it consists of three generations of specialists - Baby Boomers, Generation X, and Generation Y. Every generation has differences in capacities and capabilities, and employing them is crucial to an organization's prosperity [26] [12] [46] [65] [66]. Also, every generation comes with its own boon and perspectives towards the social setting as the social setting itself is multilayered and plays a major part in influencing the perspectives of the generations. A research occurs on the influence of national culture [86] and its outcome on generational characteristics. With a significant part of its population under 25 years, India is a youthful nation. Therefore, examining the expectations of the youth becomes even more essential. Also, understanding the requirements of the future middle managers will help in developing an understanding with the current middle managers i.e. the likely future top managers.

c) With 58 per cent of human resources, experts reveal clash among workers from different generation, understanding the generational contrasts in an Indian setting enables experts to manage such clashes. It is prescribed that organizations must be set up to utilize generational variety in order to profit the business in the long haul. This can be made possible by adjusting business objectives to the expectations of every generation so that representatives of every generation can work in collaboration. [54] states that organizations must try to improve the output from all age brackets by accommodating contrasts in the work environment. It is along these lines that teaching and developing workers to utilize this assorted generational variety for individual and hierarchical preferred standpoint becomes imperative to thrive. This will result in societies that enhance generational diversity. One such way of makes societies understand intergeneration is reverse monitoring. This may, therefore, help in opening a discourse among individuals of various ages and advancing comprehension of every others' esteem framework [45] while trading abilities and learning.

\section{Limitations}

a) Confinements of our investigation can be found in the hypothetical foundation of the ideas beginning from the GLOBE examine. There are shortcomings at the conceptualization stage, which results in a task of deciphering the investigation discoveries. Moreover, House and his associates accepted an immediate connection between values and leadership, yet such a supposition might be excessively oversimplified [6].

b) Concerning the unit of study, researches [55] [32] [18] concluded that country as a whole might not be the best way of looking at cultures. Still preference is given to national samples because of convenience it brings in studying cultural contrasts, primarily on account of their reasonable boundaries. While national culture has its binding together perspective, but we can't ignore the fact that many societal or ethnic cultures exist inside the limits of a country. In our study, we did not take the distinction of societal/ethnic culture into account. We recognize that this way we disregard the scope of different ethnicities living in the nations under investigation. 
c) The research instrument we used for survey turned out to be lengthy and may have overworked respondents. Questionnaire was administered and clarified in detail to the respondents, yet errors were observed in few of the responses.

\section{Conclusion and suggestions}

The outcomes of the study direct to a shift in the cultural values instilled in the students of India, and they no longer fall "accurately" in line with Hofstede's cultural value dimensions. It shows how the values are differing from Hofstede's cultural value dimensions. The current generation that is, tomorrow's managers, have a bit different cultural values, which show that they might not sit perfectly in a work environment as todays. Policies that run efficiently today might not work well or might not go down well with future Indian managers because of the differing cultural values. Therefore the present informational index requires a top to bottom examination, following substantiation of the first GLOBE factor construction, checks for conceivable reaction predispositions. In doing so, we will take proposals by conspicuous researchers in the field genuinely. [49] demonstrate, in view of the suspicion that culture involves something other than cultural dimensions, and thusly regarding society as a staggered, multi-layer develop might be a decent beginning stage. Here it is being referred to the fact that our society consists of many layers of backgrounds, hierarchies, orders, social groups, and strata. So to understand the depth of the gap between the different cultural values, we will need to first understand the social setting which is multifaceted and complex too.

This investigation gives suggestions to work values setting out to be distinct among the future managers and professionals of India. The study recommends that administrators must be set up to manage the new generation of managers of India through a scope of work values. Because the results came out to be falling no longer in line with Hofstede's cultural value dimensions. The accuracy of tomorrow's managers' values with that of Hofstede's is not accurate enough. It becomes imperative in such a setting to understand the present and future day needs so that the policies could be made accordingly for a better work environment. It not just creates a better work environment but ensures that there is a sound work ethics in the work area. Our professionals need to be enhanced with their present skills and be made better managers. So to achieve the same purpose there are many ways like by considering and understanding the particular drivers of a generational associate that is, to understand what drives the generation at the look to work for better management in the sector, HR experts who understand these drivers and create work environment and policies accordingly, professional guides and managers who can again create policies created for enhancing correspondence, fulfilment, responsibility, and maintenance, and advance organizational information management and efficiency.

\section{References}

[1] Altimier, L.: Leading a new generation. Newborn and infant. Nursing Reviews. Vol. 1, pp. 7-9 (2006)

[2] Amato, A.D. and Herzfeldt, R.:Learning orientation. organizational commitment and talent retention across generations. Journal of Managerial Psychology. Vol. 23 No. 8, pp. 929-953 (2008) 
[3] Bakan, D.:The duality of human existence. Chicago: Rand McN (1966)

[4] Barkema, H.G. and Vermeulen, F.: What differences in the cultural backgrounds of partners are detrimental for international joint ventures? Journal of International Business Studies. Vol. 28 No. 4, pp. 845-864 (1997)

[5] Brewer, P. and Venaik, S.: Individualism-Collectivism in Hofstede and GLOBE. Journal of International Business Studies. 42(3). 436-445 (2011)

[6] Čater, Tomaž., Lang, Rainhart. and Szabo, Erna.: Values and leadership expectations of future managers: Theoretical basis and methodological approach of the GLOBE Student project. Journal for East European Management Studies. 18. 442-462.

[7] Cennamo, L. and Gardner, D. (2008).: Generational differences in work values, outcomes and person-organisation values fit. Journal of Managerial Psychology. Vol. 23 No. 8, pp. 891-906 (2008)

[8] Chen, P.J. and Choi, Y.: Generational differences in work values: a study of hospitality management. International Journal of Contemporary Hospitality Management. Vol. 20 No. 6, pp. 595-615 (2008)

[9] Chhokar, J., Brodbeck, F. and House, R.: Culture and Leadership Across the World: The Book of In-depth Studies of 25 Societies. Lawrence Arlbaum Associates, Mahwah. NJ (2007)

[10] Connor, P.E. and Becker, B. W.: Values and the organization: Suggestions for research. Academy of Management Journal, 18. pp. 550- 561 (1975)

[11] Cyert, Richard. and James March.: A Behavioral Theory of the Firm. Englewood Cliffs. NJ: Prentice-Hall (1963)

[12] Culpin, V., Millar, C. and Peters, K.: Multi-generational frames of reference: managerial challenges of four social generations in the organization. Journal of Managerial Psychology. Vol. 30 No. 1 (2015)

[13] Dickson, M.W., Castaño, N., Magomaeva, A. and Den Hartog, D.N.: Conceptualizing leadership across cultures. Journal of World Business. 47, 4, 483-492 (2012)

[14] Erickson, T.: Generational differences between India and the US. Harvard Business Review (2009)

[15] Fernandez, D.R., Scarlson, D.S., Stepina, L.P. and Nicholson, J.D.: Hofstede's country classification 25 years later. The Journal of Social Psychology. Vol. 137 No. 1, pp. 43-54 (1997)

[16] Frieze, Irene., Olson, Josephine., Murrell, Audrey. and Selvan, Mano.: Work Values and Their Effect on Work Behavior and Work Outcomes in Female and Male Managers. Sex Roles. 54. 83-93 (2006)

[17] Gibson, J., Greenwood, R. and Murphy, E.: Generational differences in the workplace: personal values, behaviors, and popular beliefs. Journal of Diversity Management. Vol. 4 No. 3, pp. 1-7 (2009)

[18] Gould, S.J. and Grein, A.F.: Think glocally, act glocally: A culture-centric comment on Leung, Bhagat, Buchan, Erez and Gibson (2005). Journal of International Business Studies. 40, 2, 237-254 (2009)

[19] Greenberger, E., Lessard, J., Chen, C. and Farruggia, S.: Self-entitled college students: contributions of personality, parenting, and motivational factors. Journal of Youth Adolescence. Vol. 37 No. 10, pp. 1193-1204 (2008) 
[20] Gursoy, D., Maier, T.A. and Chi, C.G.: Generational differences: an examination of work values and generational gaps in the hospitality workforce. International Journal of Hospitality Management. Vol. 27 No. 3, pp. 448-458 (2008)

[21] Hall, E. T.: Beyond culture. Garden City. N.Y: Anchor Press (1976)

[22] A Hart, Karen.: Generations in the workplace: Finding common ground. MLO: medical laboratory observer. 38. 26-7 (2006)

[23] Harvey, P. and Harris, K.: Frustration-based outcomes of entitlement and the influence of supervisor communication. Human Relations. Vol. 63 No. 11, pp. 1639-1660 (2010)

[24] Harvey, P. and Martinko, M.: An empirical examination of the role of attributions in psychological entitlement and its outcomes. Journal of Organizational Behavior. Vol. 30 No. 4, pp. 459-476 (2009)

[25] Helson, R., Jones, C. and Kwan, Y.S.V.: Personality change over 40 years of adulthood: Hierarchical linear modeling analyses of two longitudinal samples. Journal of Personality \& Social Psychology. 83, 3, 752-766 (2002)

[26] Hernaus, T. and Vokic, N.P.: Work design for different generational cohorts. Journal of Organizational Change Management. Vol. 27 No. 4, pp. 615-641 (2014)

[27] Hills, M. D.: Kluckhohn and Strodtbeck's Values Orientation Theory. Online Readings in Psychology and Culture. 4(4) (2002)

[28] Hitlin, Steven. and Allyn Piliavin, Jane.: Values: Reviving a Dormant Concept. Annu Rev Sociol, 30. 359-393 (2004)

[29] Hofstede, G.: Culture's Consequences. International Differences in Work Related Values. Sage, London (1980)

[30] Hofstede, G.: The cultural relativity of organizational practices and theories. Journal of International Business Studies. Vol. 14 No. 2, pp. 75-89 (1983)

[31] Hofstede, G.: Culture's Consequences: Comparing Values, Behaviors, Institutions, and Organizations Across Nations. 2nd ed. Sage. Thousand Oaks, CA (2001)

[32] Hofstede, G.: Dimensions do not exist: A reply to Brendan McSweeney. Human Relations. 55, 11, 1355-1361 (2002)

[33] Hofstede, G.: What did GLOBE really measure? Researchers' minds versus respondents' minds. Journal of International Business Studies. 37. 882-96 (2006)

[34] Hofstede, G.: A European in Asia. Asian Journal of Social Psychology. 10(1), 16-21 (2007)

[35] Hofstede, G. and Bond, M.H.: The Confucius connection: from cultural roots to economic growth. Organizational Dynamics. Vol. 16 No. 4, pp. 5-21 (1988)

[36] Hofstede, G., \& McCrae, R.: Personality and culture revisited: Linking traits and dimensions of culture. Cross Cultural Research. 38(1): 52-88 (2004)

[37] Hoppe, M.H.: Validating the masculinity/femininity dimension on elites from 19 countries. Hofstede, G. (ed.): Masculinity and femininity: The taboo dimension of national cultures. Thousand Oaks: Sage. 29-43 (1998)

[38] House et. al.: Culture, Leadership, and Organizations. The Globe Study of 62 Societies. United Kingdom: Sage Publications (2004)

[39] Howe, N., Strauss, W. and Matson, R.J.: Millennials Rising: The Next Great Generation. Knopf Doubleday Publishing Group. New York, NY (2000)

[40] Javidan et al.: Conceptualizing and measuring cultures and their consequences: a comparative review of GLOBE's and Hofstede's approaches. Journal of International Business Studies. 37, pp. 897-914 (2006) 
[41] Judge, T. A. and Bretz, R. D.: Effects of work values on job choice decisions. Journal of Applied Psychology. 77(3), 261-271 (1992)

[42] Keating, M.A., Martin, G.S. and Szabo, E.: Do managers and students share the same perceptions of societal culture? International Journal of Intercultural Relations. 26, 6, 633652 (2002)

[43] Kirkman, B.L., Lowe, K.B. and Gibson, C.B.: A quarter century of culture's consequences: a review of empirical research incorporating Hofstede's cultural values framework. Journal of International Business Studies. Vol. 37 No. 3, pp. 285-320 (2006)

[44] Kluckhohn, F. R. and Strodtbeck, F. L.: Variations in value orientations. Evanston, IL: Row, Peterson \& Co.

[45] Koster, K.: Communication and engagement. Employee Benefit News (2013)

[46] Kultalahti, S. and Viitala, R.: Generation Y - challenging clients for HRM? Journal of Managerial Psychology. Vol. 30 No. 1, pp. 101-114 (2015)

[47] Lamm, E. and Meeks, M.D.: Workplace fun: the moderating effects of generational differences. Employee Relations. Vol. 31 No. 6, pp. 613-631 (2009)

[48] Latham, G.P. and Pinder, C.C.: Work Motivation Theory and Research at the Dawn of the Twenty-First Century. Annual Review of Psychology. 56, 485-516 (2005)

[49] Leung, K., Bond, M.H., Reimel de Carrasquel, S., MuFioz, C., Hernandez, M., Murakami, F., Yamaguchi, S., Bierbrauer, G. and Singelis, T.M.: Social axioms: the search for universal dimensions of general beliefs about how the world functions. Journal of CrossCultural Psychology 33(3): 286-302 (2002)

[50] Levitin, T.: 'Values', In: J.P. Robinson and P.R. Shaver (eds.) Measures of Social Psychological Attitudes. Institute Social Research: Ann Arbor, MI, pp. 489-502 (1973)

[51] Lowe, D., Levitt, K. and Wilson, T.: Solutions for retaining Generation Y employees in the workplace. Business Renaissance Quarterly. Vol. 3 No. 3, pp. $43-57$ (2008)

[52] McClelland, D.C.: The achieving society. Princeton: Van Nostrand (1961)

[53] McClelland, D.C.: Human motivation. Cambridge: Cambridge University Press (1987) [54] McGuire, D., By, R.T. and Hutchings, K.: Towards a model of human resource solutions for achieving intergenerational interaction in organizations. Journal of European Industrial Training. Vol. 31 No. 8, pp. 592-608 (2007)

[55] McSweeney, B.: Hofstede's model of national cultural differences and their consequences: A triumph of faith - a failure of analysis. Human Relations. 55,1, 89-118 (2002)

[56] Mead, R.: International management: Cross-cultural dimensions. Maiden: Blackwell (1998)

[57] Meglino, B. and Ravlin, E.: Individual Values in Organizations: Concepts, Controversies, and Research. Journal of Management. 24, 351-389 (1998)

[58] Merritt, M.: Virtue Ethics and Situationist Personality Psychology. Ethical Theory and Moral Practice. 3(4), 365-383 (2000)

[59] Mulder, M.: The daily power game. Leydem: Martinus Nijhoff (1977)

[60] Ng, E.S.W., Schweitzer, L. and Lyons, S.T.: New generation, great expectations: a field study of the millennial generation. Journal of Business and Psychology. Vol. 25 No. 2, pp. 281-292 (2010)

[61] Parsons, T.: Essays in sociological theory: Pure and applied. New York: Free Press (1949) 
[62] Plew, S.: Retaining young talent in your organisation. Business People. September, p. 32 (2013)

[63] Rani, Nitya. and Samuel, Anand.: A study on generational differences in work values and person-organization fit and its effect on turnover intention of Generation $\mathrm{Y}$ in India. Management Research Review. Vol. 39 Issue: 12, pp.1695-1719 (2016)

[64] Real, K., Mitnick, A. and Maloney, W.: More similar than different: millennials in the US building trades. Journal of Business and Psychology. Vol. 25 No. 2, pp. 303-313 (2010) [65] Rentz, K.C.: Beyond the generational stereotypes: a study of US Generation Y employees in context. Business Communication Quarterly. Vol. 77 No. 4, pp. 136-166 (2014) [66] Reuteman, R.: Generation gaps. Entrepreneur. Vol. 43 No. 3, pp. $42-48$ (2015)

[67] Reynolds, L., Bush, E.C. and Geist, R.: The Gen Y imperative. Communication World. Vol. 25 No. 2, pp. 19-22 (2008)

[68] Roe, R.A. and Ester, P.: Values and work: empirical findings and theoretical perspective. Applied Psychology. Vol. 48 No. 1, pp. 1-21 (1999)

[69] Rokeach, M.: The nature of human values. New York: Free Press (1973)

[70] Ronen, Simcha. and Shenkar, Oded.: Clustering Countries on Attitudinal Dimensions: A Review and Synthesis. Academy of Management Review. 10. 435-454 (1985)

[71] Schwartz, S. H.: Are there universal aspects in the structure and contents of human values? Journal of Social Issues. 50(4), 19-45 (1994)

[72] Schwartz, S. H.: A theory of cultural values and some implications for work. Applied Psychology. 48, 23-47 (1999)

[73] Shapira, Zur. and Griffith, Terri.: Comparing the work values of engineers with managers, production, and clerical workers: A multivariate analysis. Journal of Organizational Behavior. 11, 281 - 292 (1990)

[74] Shi, X. and Wang, J.: Interpreting Hofstede model and GLOBE model: which way to go for cross-cultural research? International Journal of Business and Management. Vol. 6 No. 5, pp. 93-99 (2011)

[75] Smith, P.B.: When elephants fight, the grass gets trampled: The GLOBE and Hofstede projects. Journal of International Business Studies. 37, 6, 915-921 (2006)

[76] Smola, K.W. and Sutton, C.D.: Generational differences: revisiting generational work values for the new millennium. Journal of Organizational Behavior. Vol. 23 No. 4, pp. 363 382 (2002)

[77] Super, D. E.: Work values inventory manual. Boston: Houghton Mifflin (1970)

[78] Tang, L. and Koveos, P.E.: A framework to update Hofstede's cultural value indices: economic dynamics and institutional stability. Journal of International Business Studies. Vol. 39. No. 6, pp. 1045-1063 (2008)

[79] Taras, V., Steel, P. and Kirkman, B.L.: Improving national culture indices using a longitudinal meta-analysis of Hofstede's dimensions. Journal of World Business. Vol. 47 No. 3, pp. 329-341 (2012)

[80] Triandis et al.: The measurement of etic aspect of individualism and collectivism across cultures. Australian Journal of Psychology - AUST J PSYCHOL, 38, 257-267 (1986)

[81] Trompenaars, F.: Riding the Waves of Culture: Understanding Cultural Diversity in Business. Nicholas Brealey Publ. London (1993)

[82] Twenge, J.M., Konrath, S., Foster, J.D., Campbell, W.K. and Bushman, B.J.: Egos inflating over time: a cross-temporal meta-analysis of the Narcissistic personality inventory. Journal of Personality. Vol. 76 No. 4, pp. 875-902 (2008) 
[83] Twenge, J.M. and Campbell, K.W.: The Narcissism Epidemic: Living In The Age of Entitlement. Simon and Schuster Adult Publishing Group. New York, NY (2010)

[84] Venaik, S. and Brewer, P.: Avoiding uncertainty in Hofstede and GLOBE. Journal of International Business Studies. Vol. 41 No. 8, pp. 1294-1315 (2010)

[85] Wong, M., Gardiner, E., Lang, W. and Coulon, L.: Generational differences in personality and motivation. Journal of Managerial Psychology. Vol. 23 No. 8, pp. 878-890 (2008)

[86] Yi, X., Ribbens, B., Fu, L. and Cheng, W.: Variation in career and workplace attitudes by generation, gender, and culture differences in career perceptions in the United States and China. Employee Relations. Vol. 37 No. 1, pp. 66-82 (2015) 